Jurnal Sistem Informasi (Journal of Information Systems). 2/13 (2017), 97-102

DOI: http://dx.doi.org/10.21609/jsi.v13i2.553

\title{
EFEKTIVITAS PELATIHAN SERTIFIKASI KOMPUTER DASAR MENGGUNAKAN TEORY ROUGH SET DAN PROGRAM ROSSETA
}

\author{
${ }^{1}$ Karmila Suryani dan ${ }^{2}$ Khairudin \\ ${ }^{1}$ Pendidikan Teknik Informatika dan Komputer, ${ }^{2}$ Pendidikan Matematika, FKIP UBH, Jl. Sumatra Ulak \\ Karang Padang, Sumatera Barat, 25133, Indonesia \\ 1Karmilasuryani.ptik@gmail.com, ${ }^{2}$ khairudin@bunghatta.ac.id
}

\begin{abstract}
This study aims to determine the effectiveness of basic computer training with Rough set theory. Through Rough set theory found a new rule and knowledge to take a decision about the effectiveness of the Training Office Desktop training program. The training materials consist of mastering Excel, Word and Power point applications for office data processing. The training was conducted during Informatics and Computer Engineering Education, FKIP Bung Hatta University in cooperation with Microsoft and international standard. This research uses descriptive method which is adjusted with Rough set theory steps. The sample used is 35 participants. Results obtained from 35 samples found that the effectiveness of this training is $100 \%$. Through the process of equivalence class obtained 86 rules reduced to 24 rules. For simulation the established system was tested with the Rosseta application program
\end{abstract}

Keywords: effectiveness, rough sets theory, rosseta application

\begin{abstract}
Abstrak
Penelitian ini bertujuan untuk menentukan efektivitas pelatihan komputer dasar dengan teori Roughset. Melalui teori Roughset ditemukan rule dan knowledge baru guna mengambil sebuah keputusan mengenai efektivitas program pelatihan Desktop Office Training. Materi pelatihan terdiri dari penguasaan aplikasi Excel, Word dan Power point untuk pengolahan data perkantoran. Pelatihan ini dilaksanakan di program studi Pendidikan Teknik Informatika dan Komputer, FKIP Universitas Bung Hatta yang bekerjasama dengan Microsoft dan berstandar Internasional. Penelitian ini menggunakan metoda deskriptif yang disesuaikan dengan langkah-langkah teori Rough set. Sampel yang digunakan sebanyak 35 peserta. Hasil yang diperoleh dari 35 sampel didapat bahwa tingkat keefektifan pelatihan ini adalah $100 \%$. Melalui proses equivalence class diperoleh 86 rule yang tereduksi menjadi 24 rule. Untuk simulasi sistem yang terbentuk diuji dengan program aplikasi Rosseta.
\end{abstract}

Kata Kunci: efektivitas, teori rough set, applikasi rosseta

\section{Pendahuluan}

Progam studi pendidikan Teknik Informatika dan Komputer merupakan program studi di Universitas Bung Hata yang sudah mempersiapkan sertifikat kompetensi bagi lulusan. Salah satu uji kompetensi yang telah dilakukan adalah desktop office training (pelatihan komputer dasar) yang bekerjasama dengan Trust Microsoft Partner. Pelatihan bertujuan untuk membekali alumni untuk siap pakai dalam pengolahan data administrasi perkantoran dengan menguasai Microsoft Office. Pentingnya menguasai Teknologi Informasi dan Komunikasi (TIK) karena disadari telah mempengaruhi berbagai aspek pengetahuan dan kehidupan masyarakat di era informasi ini. Menurut [4] menyatakan bahwa ma- syarakat era informasi lebih memusatkan pada aset pengetahuan dibandingkan dengan aset modal. Hal ini mengisyaratkan semua komponen masyarakat harus menguasai TIK dalam menyelesaikan masalah yang terkait dengan pekerjaannya. Disamping itu UNESCO juga menyatakan bahwa abad 21 merupakan cara belajar sepanjang hayat (long life education) yang berarti bahwa pembudayaan penggunaan TIK oleh setiap komponen masyarakat akan menjadi bekal saat belajar tidak hanya diruang kelas namun dapat dilakukan dimana saja, kapan saja dan belajar apa saja.

Uji kompetensi komputer dasar yang dilaksanakan melalui pelatihan Microsoft Office 2010 telah menghasilkan 100 orang lulusan yang sekarang sudah tersebar diberbagai propinsi. Namun perlu 
adanya analisa tentang sejauh mana keefektifan uji kompetensi mahasiswa melalui pelatihan komputer dasar ini. Salah satu cara yang dapat dilakukan dalam pengambilan keputusan tingkat keefektifan sebuah pelatihan adalah menggunakan teori rough set dan dibandingkan dengan program aplikasi rosseta. Teori rough set dapat menentukan peluang kelulusan bagi mahasiswa dalam uji kompetensi melalui rule dan knowledge yang dihasilkan [7]. Dengan demikian teori Rough set ini juga dapat memberikan sebuah rule dan knowledge dalam menentukan keefektifan pelatihan komputer dasar.

Efektivitas pelatihan dapat diukur dari hasil akhir pelatihan. Indikator yang dapat terlihat adalah bertambahnya pengetahuan, keterampilan dan kemampuan peserta pelatihan sehingga mereka dapat bekerja lebih baik. Terdapat empat ukuran dari efektivitas pelatihan, yaitu: reaksi, proses belajar, perubahan perilaku dan hasil [1]. Reaksi merupakan ukuran keefektivitasan pelatihan yang dilihat dari reaksi para peserta pelatihan, terutama reaksi yang bersifat langsung. Proses belajar merupakan ukuran keefektivitasan pelatihan yang dilihat dari seberapa besar peserta pelatihan mampu menyerap ilmu pengetahuan yang diberikan dalam pelatihan. Pengukuran efektivitas dengan menggunakan regresi berganda dengan indikator tingkat reaksi, tingkat pembelajaran, tingkat perubahan perilaku yang mempengaruhi tingkat kinerja pegawai sesudah mengikuti pelatihan sudah diteliti oleh [6]. Selanjutnya [2] menggunakan model analisis Interaktif Miles dan Huberman dalam menganalisis efektivitas pelatihan pendidikan dan pelatihan kepemimpinan pegawai negeri sipil di kabupaten Probolinggo. Dalam tulisan ini hanya menggunakan satu level dari model Kirkpatrick untuk mengevaluasi efektivitas pelatihan, yaitu dengan melihat hasil (Result) pelatihan dan sesuai dengan pendapat [1].

\section{Teori Rough set}

Rough set adalah sebuah teknik matematika yang dikembangkan oleh Pawlack pada tahun 1980. Teknik ini digunakan untuk menangani masalah un-

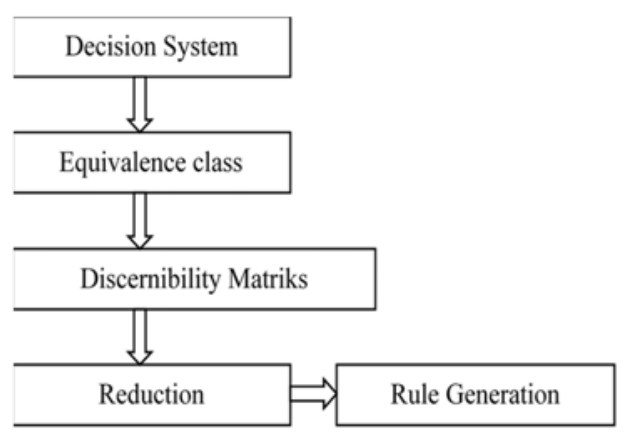

Gambar 1. Proses Penemuan Knowledge dengan Rough certainty (missing data, incompleted data, inconsistency, data imprecision dan vagueness) dalam aplikasi Artificial Intelligence (AI).Teori Rough set membagi data ke dalam kelas upper approximation, lower approximation dan boundary. Daerah rough (boundary) dalam klasifikasi Rough set dapat didekati dengan perhitungan quantitative measure. Teori Rough set akan diimplementasikan dan dikembangkan dengan dasar queri SQL. Dengan Rough set, dimungkinkan untuk menemukan hubungan tersembunyi dan reduct atribut dari serangkaian klasifikasi data atribut. Dari reduct tersebut dapat di-generate rules, dan dihitung quantitative measures untuk memperkuat rule tersebut. Rule ya-ng diperkuat quantitative measure digunakan un-tuk mengklasifikasi data.

\section{Atribut dalam Rough set}

Suatu observasi, example, pattern (pola) atau obyek biasanya ditandai oleh beberapa atribut. Misalnya obyek orang, bisa ditandai dengan atribut tinggi badan, berat badan, bentuk muka, dan lain. Atribut ini sering juga disebut dengan variabel. Dari sederet variabel akan dikelompokkan menjadi input (variabel independent, predictor) dan output (variabel dependent, respons atau label). Dalam penulisan penelitian ini representasi data disajikan dalam bentuk tabel yang terdiri atas kolom dan baris. Baris menyatakan obyek atau observasi dan kolom menyatakan atribut atau variabel.

Pada sebuah database terdapat dua jenis atribut yaitu atribut kondisi dan atribut keputusan yang kadang disebut atribut kelas. Sedangkan pada rough set terdapat dua buah atribut yang digunakan yaitu:

Atribut Kondisi (conditional attribute)

Atribut kondisi merupakan satu-satunya yang akan mewakili pengetahuan yang akan memelihara kedapatan dilihat antara objek-objek dengan menggunakan fungsi-fungsi kepadatan [5]

TABEL 1

\begin{tabular}{llll}
\multicolumn{4}{c}{ ANGKA MUTU PENILAIAN } \\
\hline $\begin{array}{c}\text { Angka Mutu } \\
(\text { AM) }\end{array}$ & $\begin{array}{c}\text { Nilai Huruf } \\
(\text { NF) }\end{array}$ & \multicolumn{2}{c}{ Keterangan } \\
\hline $0-49$ & E & Tidak Lulus & 0 \\
$50-59$ & D & Lulus & 1 \\
$60-69$ & C & & \\
$70-79$ & B & & \\
$80-100$ & A & & \\
\hline
\end{tabular}

TABEL 2

SIMBOL DARI MASING-MASING ATRIBUT KONDISI

\begin{tabular}{ll}
\hline \multicolumn{1}{c}{ Atribut } & Simbol \\
\hline Nilai Word & $\mathrm{P}$ \\
Nilai Excel & $\mathrm{Q}$ \\
Nilai Powet Point & $\mathrm{R}$ \\
Nilai Rata-rata & $\mathrm{S}$ \\
Keterangan & $\mathrm{T}$ \\
\hline
\end{tabular}


TABEL 3

\begin{tabular}{llllllll}
\multicolumn{1}{c}{ EQUIVALENCE CLASS SECARA LENGKAP } \\
\hline Class & $\mathrm{P}$ & $\mathrm{Q}$ & $\mathrm{R}$ & $\mathrm{S}$ & $\mathrm{T}$ & $\mathrm{U}$ & Jumlah Obyek \\
\hline EC1 & 1 & 1 & 1 & 1 & 1 & 1 & 28 \\
EC2 & 1 & 1 & 0 & 0 & 0 & 2 & 1 \\
EC3 & 1 & 0 & 0 & 0 & 0 & 3 & 4 \\
EC4 & 0 & 0 & 0 & 0 & 0 & 4 & 2 \\
\hline
\end{tabular}

TABEL 4

\begin{tabular}{ll} 
& \multicolumn{1}{c}{ DECISION SYSTEM } \\
\hline Decision & \multicolumn{1}{c}{ Sampel } \\
\hline $100 \%$ & $\mathrm{~S}_{1}, \mathrm{~S}_{2}, \mathrm{~S}_{3}, \mathrm{~S}_{4}, \mathrm{~S}_{5}, \mathrm{~S}_{6}, \mathrm{~S}_{7}, \mathrm{~S}_{9}, \mathrm{~S}_{10}, \mathrm{~S}_{11}, \mathrm{~S}_{12}, \mathrm{~S}_{13}$, \\
& $\mathrm{S}_{14}, \mathrm{~S}_{19}, \mathrm{~S}_{20}, \mathrm{~S}_{21}, \mathrm{~S}_{22}, \mathrm{~S}_{23}, \mathrm{~S}_{24}, \mathrm{~S}_{25}, \mathrm{~S}_{26}, \mathrm{~S}_{27}$, \\
& $\mathrm{S}_{29}, \mathrm{~S}_{30}, \mathrm{~S}_{32}, \mathrm{~S}_{33}, \mathrm{~S}_{34}, \mathrm{~S}_{35}, \mathrm{~S}_{36}$ \\
$40 \%$ & $\mathrm{~S}_{31}$ \\
$20 \%$ & $\mathrm{~S}_{8}, \mathrm{~S}_{15}, \mathrm{~S}_{16}, \mathrm{~S}_{17}$ \\
$0 \%$ & $\mathrm{~S}_{18}, \mathrm{~S}_{28}$ \\
\hline
\end{tabular}

\section{Atribut Keputusan}

Atribut Keputusan (decision attribute), yaitu pengetahuan yang diungkapkan oleh salah satu atau beberapa atribut dari atribut kondisi. Atribut keputusan berhubungan dengan konsep-konsep (kelas-kelas) yang tergambar dalam sebuah aturan. Biasanya, sebuah atribut keputusan yang tunggal sudah merupakan semua yang dibutuhkan.

\section{Metode}

Jenis penelitian ini adalah penelitian deskriptif yang menganalisa dan mendeskripsikan melalui instrumen yang tepat untuk memperoleh tujuan yang hendak dicapai. Penelitian deskriptif merupakan metode penelitian yang berusaha menggambarkan objek atau subjek yang diteliti sesuai dengan apa adanya, dengan tujuan menggambarkan secara sistematis fakta dan karakteristik objek yang diteliti secara tepat. Aplikasi Rough set telah banyak digunakan dalam beberapa riset diantaranya [7] dalam mendiagnosa penyakit Medirose dan [8] dalam menentukan peringkat kualitas sejumlah aplikasi berbasis objek,

Instrumen yang digunakan dalam penelitian ini diantaranya hasil test uji Kompetensi yang sudah distandarisasi oleh Microsoft untuk uji kompetensi. Untuk pengolahan data hasil penelitian menggunakan teory Rough set dan program aplikasi Rosseta. Data dianalisis dengan mengklasifikasi nilai perolehan tiap materi uji berdasarkan standar kelulusan menurut Microsof. Nilai rata-rata lulus adalah jika mencapai skor minimal 50. Melalui Rough set ditentukan prediksi peluang kelulusan mahasiswa dalam uji kompetensi Microsoft office 2010. Untuk menemukan sebuah knowledge tentang peluang kelulusan dengan teori Rough set. Sampel diambil sebanyak 35 orang $(35 \%)$ secara acak dengan mempertimbangkan homogenitas individu. Selanjutnya dilakukan langkah-langkah perancangan sistim seperti terlihat pada Gambar 1 .
TABEL 5

\begin{tabular}{llllllll}
\multicolumn{7}{c}{ DATA EQUIVALNCE CLASS } \\
\hline Class & $\mathrm{P}$ & $\mathrm{Q}$ & $\mathrm{R}$ & $\mathrm{S}$ & $\mathrm{T}$ & $\mathrm{U}$ & Jumlah \\
\hline $\mathrm{EC}_{1}$ & $\mathrm{~A}$ & $\mathrm{C}$ & $\mathrm{C}$ & $\mathrm{C}$ & 1 & 1 & 1 \\
$\mathrm{EC}_{2}$ & $\mathrm{~B}$ & $\mathrm{D}$ & $\mathrm{D}$ & $\mathrm{C}$ & 1 & 1 & 5 \\
$\mathrm{EC}_{3}$ & $\mathrm{~A}$ & $\mathrm{~B}$ & $\mathrm{C}$ & $\mathrm{B}$ & 1 & 1 & 2 \\
$\mathrm{EC}_{4}$ & $\mathrm{~A}$ & $\mathrm{D}$ & $\mathrm{D}$ & $\mathrm{C}$ & 1 & 1 & 3 \\
$\mathrm{EC}_{5}$ & $\mathrm{~A}$ & $\mathrm{C}$ & $\mathrm{B}$ & $\mathrm{B}$ & 1 & 1 & 1 \\
$\mathrm{EC}_{6}$ & $\mathrm{~B}$ & $\mathrm{E}$ & $\mathrm{E}$ & $\mathrm{E}$ & 0 & 3 & 2 \\
$\mathrm{EC}_{7}$ & $\mathrm{C}$ & $\mathrm{D}$ & $\mathrm{C}$ & $\mathrm{C}$ & 1 & 1 & 2 \\
$\mathrm{EC}_{8}$ & $\mathrm{D}$ & $\mathrm{E}$ & $\mathrm{E}$ & $\mathrm{E}$ & 0 & 3 & 1 \\
$\mathrm{EC}_{9}$ & $\mathrm{C}$ & $\mathrm{E}$ & $\mathrm{E}$ & $\mathrm{E}$ & 0 & 3 & 1 \\
$\mathrm{EC}_{10}$ & $\mathrm{E}$ & $\mathrm{E}$ & $\mathrm{E}$ & $\mathrm{E}$ & 0 & 4 & 2 \\
$\mathrm{EC}_{11}$ & $\mathrm{C}$ & $\mathrm{B}$ & $\mathrm{C}$ & $\mathrm{C}$ & 1 & 1 & 2 \\
$\mathrm{EC}_{12}$ & $\mathrm{D}$ & $\mathrm{B}$ & $\mathrm{D}$ & $\mathrm{C}$ & 1 & 1 & 1 \\
$\mathrm{EC}_{13}$ & $\mathrm{~B}$ & $\mathrm{~A}$ & $\mathrm{~B}$ & $\mathrm{~B}$ & 1 & 1 & 1 \\
$\mathrm{EC}_{14}$ & $\mathrm{~B}$ & $\mathrm{~A}$ & $\mathrm{~A}$ & $\mathrm{~A}$ & 1 & 1 & 1 \\
$\mathrm{EC}_{15}$ & $\mathrm{D}$ & $\mathrm{C}$ & $\mathrm{D}$ & $\mathrm{D}$ & 1 & 1 & 1 \\
$\mathrm{EC}_{16}$ & $\mathrm{~A}$ & $\mathrm{~B}$ & $\mathrm{~A}$ & $\mathrm{~A}$ & 1 & 1 & 1 \\
$\mathrm{EC}_{17}$ & $\mathrm{C}$ & $\mathrm{C}$ & $\mathrm{C}$ & $\mathrm{C}$ & 1 & 1 & 1 \\
$\mathrm{EC}_{18}$ & $\mathrm{D}$ & $\mathrm{A}$ & $\mathrm{D}$ & $\mathrm{C}$ & 1 & 1 & 1 \\
$\mathrm{EC}_{19}$ & $\mathrm{D}$ & $\mathrm{D}$ & $\mathrm{E}$ & $\mathrm{E}$ & 0 & 2 & 1 \\
$\mathrm{EC}_{20}$ & $\mathrm{C}$ & $\mathrm{D}$ & $\mathrm{A}$ & $\mathrm{C}$ & 1 & 1 & 1 \\
$\mathrm{EC}_{21}$ & $\mathrm{D}$ & $\mathrm{D}$ & $\mathrm{C}$ & $\mathrm{D}$ & 1 & 1 & 1 \\
$\mathrm{EC}_{22}$ & $\mathrm{C}$ & $\mathrm{D}$ & $\mathrm{D}$ & $\mathrm{D}$ & 1 & 1 & 1 \\
$\mathrm{EC}_{23}$ & $\mathrm{~A}$ & $\mathrm{~B}$ & $\mathrm{D}$ & $\mathrm{B}$ & 1 & 1 & 1 \\
$\mathrm{EC}_{24}$ & $\mathrm{~A}$ & $\mathrm{D}$ & $\mathrm{C}$ & $\mathrm{C}$ & 1 & 1 & 1 \\
\hline
\end{tabular}

\section{Hasil dan Analisis}

Langkah-langkah untuk menemukan nilai dari atribut keputusan dan dalam penentuan keefektifan pelatihan setifikasi komputer dasar di prodi Pendidikan Teknik Informatika dan Komputer yaitu:

Lakukan klasifikasi atribut kondisi seperti Nilai Word (P), Nilai Excel (Q), Nilai Power Point (R), Nilai Rata-rata (S), Keterangan (T) menggunakan metode unary encoding dan categorical data sesuai dengan Keputusan Memteri Naisonal Nomor 232/U/2000 tentang Pedoman Penyusunan Kurikulum Perguruan Tinggi dan Penilaian Hasil Belajar Mahasiswa sebagaimana ditunjukkan pada Tabel 1. Aribut kondisi yang digunakan disimbolkan seperti tersaji pada Tabel 2. Sedangkan attribut keputusanya adalah Keefektifan Pelatihan (U).

Berdasarkan Tabel 1 dan Tabel 2 maka dilakukan proses transformasi data 1 dengan cara mengubah nilai angka yang terdapat pada masingmasing atribut kondisi menjadi nilai huruf, seperti terlihat pada Lampiran Tabel I.

Proses perhitungan untuk melengkapi nilai atribut keputusan (U) sebagai berikut sekalugus sebagai acuan persentase keefektifan pelatihan sertifikasi kompetensi komputer dasar. Perhitungan ini didapat berdasarkan equivalence class yang datanya menjadi 24 sampel.

$$
E C_{1}=\frac{1+1+1+1+1}{5}=\frac{5}{5}=1 * 100 \%=100 \% \rightarrow 1
$$




$$
\begin{array}{ll}
E C_{2}=\frac{1+1+0+0+0}{5}=\frac{2}{5} * 100 \%=40 \% & \rightarrow 2 \\
E C_{3}=\frac{1+0+0+0+0}{5}=\frac{1}{5} * 100 \%=20 \% & \rightarrow 3 \\
E C_{4}=\frac{0+0+0+0+0}{5}=\frac{0}{5} * 100 \%=0 \% & \rightarrow 4
\end{array}
$$

Berdasarkan perhitungan di atas, maka dihasilkan equvalence class untuk atribut keputusan seperti Tabel 3.

\section{Langkah-langkah Teori Rough set}

Decision System

Berdasarkan hasil perhitungan equivalence class untuk atribut keputusan maka dapat dilihat informasi tentang pengelompokan keefektifan pelatihan seperti Tabel 4.

Equivalence Class

Setelah mendapatkan hasil dari decission system, maka semua sampel dikelompokan sesuai dengan perhitungan equivalece class seperti Tabel 5.

\section{Discernibility Matrix dan Reduct}

Berdasarkan Tabel 6 (numerical representasi equivalence class) maka dapat disusun discernibility matrix, dan discernibility matrix modulo $\mathrm{D}$, yang selanjutnya menghasilkan reduct seperti Lampiran Table II.

\section{Rule Generation}

Pengetahuan baru yang terbentuk dituliskan melalui rule generation, dimana rule-rule tersebut dirujuk dari hasil reducts, kemudian dicocokkan deng-

TABEL 7

EQUIVALENCE CLASS

\begin{tabular}{lllllll}
\multicolumn{7}{c}{ EQUIVALENCE CLASS } \\
\hline Class & $\mathrm{P}$ & $\mathrm{Q}$ & $\mathrm{R}$ & $\mathrm{S}$ & $\mathrm{T}$ & $\mathrm{U}$ \\
\hline $\mathrm{EC}_{1}$ & $\mathrm{~A}$ & $\mathrm{C}$ & $\mathrm{C}$ & $\mathrm{C}$ & 1 & 1 \\
$\mathrm{EC}_{2}$ & $\mathrm{~B}$ & $\mathrm{D}$ & $\mathrm{D}$ & $\mathrm{C}$ & 1 & 1 \\
$\mathrm{EC}_{3}$ & $\mathrm{~A}$ & $\mathrm{~B}$ & $\mathrm{C}$ & $\mathrm{B}$ & 1 & 1 \\
$\mathrm{EC}_{4}$ & $\mathrm{~A}$ & $\mathrm{D}$ & $\mathrm{D}$ & $\mathrm{C}$ & 1 & 1 \\
$\mathrm{EC}_{5}$ & $\mathrm{~A}$ & $\mathrm{C}$ & $\mathrm{B}$ & $\mathrm{B}$ & 1 & 1 \\
$\mathrm{EC}_{6}$ & $\mathrm{~B}$ & $\mathrm{E}$ & $\mathrm{E}$ & $\mathrm{E}$ & 0 & 3 \\
$\mathrm{EC}_{7}$ & $\mathrm{C}$ & $\mathrm{D}$ & $\mathrm{C}$ & $\mathrm{C}$ & 1 & 1 \\
$\mathrm{EC}_{8}$ & $\mathrm{D}$ & $\mathrm{E}$ & $\mathrm{E}$ & $\mathrm{E}$ & 0 & 3 \\
$\mathrm{EC}_{9}$ & $\mathrm{C}$ & $\mathrm{E}$ & $\mathrm{E}$ & $\mathrm{E}$ & 0 & 3 \\
$\mathrm{EC}_{10}$ & $\mathrm{E}$ & $\mathrm{E}$ & $\mathrm{E}$ & $\mathrm{E}$ & 0 & 4 \\
$\mathrm{EC}_{11}$ & $\mathrm{C}$ & $\mathrm{B}$ & $\mathrm{C}$ & $\mathrm{C}$ & 1 & 1 \\
$\mathrm{EC}_{12}$ & $\mathrm{D}$ & $\mathrm{B}$ & $\mathrm{D}$ & $\mathrm{C}$ & 1 & 1 \\
$\mathrm{EC}_{13}$ & $\mathrm{~B}$ & $\mathrm{~A}$ & $\mathrm{~B}$ & $\mathrm{~B}$ & 1 & 1 \\
$\mathrm{EC}_{14}$ & $\mathrm{~B}$ & $\mathrm{~A}$ & $\mathrm{~A}$ & $\mathrm{~A}$ & 1 & 1 \\
$\mathrm{EC}_{15}$ & $\mathrm{D}$ & $\mathrm{C}$ & $\mathrm{D}$ & $\mathrm{D}$ & 1 & 1 \\
$\mathrm{EC}_{16}$ & $\mathrm{~A}$ & $\mathrm{~B}$ & $\mathrm{~A}$ & $\mathrm{~A}$ & 1 & 1 \\
$\mathrm{EC}_{17}$ & $\mathrm{C}$ & $\mathrm{C}$ & $\mathrm{C}$ & $\mathrm{C}$ & 1 & 1 \\
$\mathrm{EC}_{18}$ & $\mathrm{D}$ & $\mathrm{A}$ & $\mathrm{D}$ & $\mathrm{C}$ & 1 & 1 \\
$\mathrm{EC}_{19}$ & $\mathrm{D}$ & $\mathrm{D}$ & $\mathrm{E}$ & $\mathrm{E}$ & 0 & 2 \\
$\mathrm{EC}_{20}$ & $\mathrm{C}$ & $\mathrm{D}$ & $\mathrm{A}$ & $\mathrm{C}$ & 1 & 1 \\
$\mathrm{EC}_{21}$ & $\mathrm{D}$ & $\mathrm{D}$ & $\mathrm{C}$ & $\mathrm{D}$ & 1 & 1 \\
$\mathrm{EC}_{22}$ & $\mathrm{C}$ & $\mathrm{D}$ & $\mathrm{D}$ & $\mathrm{D}$ & 1 & 1 \\
$\mathrm{EC}_{23}$ & $\mathrm{~A}$ & $\mathrm{~B}$ & $\mathrm{D}$ & $\mathrm{B}$ & 1 & 1 \\
$\mathrm{EC}_{24}$ & $\mathrm{~A}$ & $\mathrm{D}$ & $\mathrm{C}$ & $\mathrm{C}$ & 1 & 1 \\
\hline & & & & & &
\end{tabular}

an data yang sebenarnya. Hal ini dapat dilihat pada Tabel 7.

Dari beberapa ilustrasi rule-rule yang terlihat, maka dapat dihasilkan knowledge baru sebagai berikut:

$\{\mathrm{P}, \mathrm{Q}, \mathrm{R}, \mathrm{S}, \mathrm{T}\}=\mathrm{U}_{1}$ IF Nilai Ms. Word = "A" AND Nilai Ms. Excel = "C" AND Nilai Ms. Power Point = "C" AND Nilai Rata-rata $=$ "C" AND Keterangan $=$ " $1 "$ THEN Persentase Keefektifan $=$ "100\%".

$\mathrm{R}, \mathrm{S}\}=\mathrm{U}_{3}$

IF Nilai Ms. Power Point $=$ "C " AND Nilai Ratarata $=$ "C" THEN Persentase Keefektifan $=$ " $20 \% "$

$\{\mathrm{Q}\}=\mathrm{U}_{3}$

IF Nilai Ms. Excel = "E " THEN Persentase Keefektifan $=" 20 \% "$

$\{\mathrm{T}\}=\mathrm{U}_{3}$

IF Nilai Keterangan $=$ " 1 " THEN Persentase Keefektifan $=$ " $20 \% "$

Sementara hasil pengujian dengan program aplikasi Rosseta, rule yang terbentuk adalah 86 rule seperti Tabel 8.

Setelah melalui tahap persiapan dan pelaksanaan penelitian maka dari 35 sampel yang analisis, dengan langkah dari teori roungset terlihat dalam proses equivalence class diperoleh sampel sebanyak 24 buah. Semua sampel yang sudah digabung tersebut dikelompokan menjadai tingkat keefektifan pelatihan menjadi a) $100 \%$, b) $40 \%$, c) $20 \%$ dan d) $0 \%$.' Data yang dihasilkan dari proses reduct dan generating rule membuktikan bahwa dari 24 kombinasi rule yang tertulis terlihat bahwa pelatihan sertifikasi komputer dasar ini (Microsoft Office

TABEL 8

HASIL PENGUJIAN DENGAN APLIKASI ROSSETA

\begin{tabular}{lll}
\hline No. & Rule & \\
\hline 1 & Class(EC1) $=>$ Keefektifan Pelatihan(1) \\
2 & Class(EC2) $=>$ Keefektifan Pelatihan(1) \\
3 & Class(EC3) $=>$ Keefektifan Pelatihan(1) \\
4 & Class(EC4) $=>$ Keefektifan Pelatihan(1) \\
5 & Class(EC5) $=>$ Keefektifan Pelatihan(1) \\
6 & Class(EC6) $=>$ Keefektifan Pelatihan(3) \\
7 & Class(EC7) $=>$ Keefektifan Pelatihan(1) \\
8 & Class(EC8) $=>$ Keefektifan Pelatihan(3) \\
9 & Class(EC9) $=>$ Keefektifan Pelatihan(3) \\
10 & Class(EC10) $=>$ Keefektifan Pelatihan(4) \\
11 & Class(EC11) $=>$ Keefektifan Pelatihan(1) \\
12 & Class(EC12) $=>$ Keefektifan Pelatihan(1) \\
13 & Class(EC13) $=>$ Keefektifan Pelatihan(1) \\
14 & Class(EC14) $=>$ Keefektifan Pelatihan(1) \\
15 & Class(EC15) $=>$ Keefektifan Pelatihan(1) \\
16 & Class(EC16) $=>$ Keefektifan Pelatihan(1) \\
17 & Class(EC17) $=>$ Keefektifan Pelatihan(1) \\
18 & Class(EC18) $=>$ Keefektifan Pelatihan(1) \\
19 & Class(EC19) $=>$ Keefektifan Pelatihan(2) \\
20 & Class(EC20) $=>$ Keefektifan Pelatihan(1) \\
\hline
\end{tabular}


2010) efektif dilakukan dengan persentasi tingkat keefektifan $100 \%$.

Melalui pengujian keefektifan dengan program applikasi Rosseta juga terbukti bahwa pelatihan ini efektif dilakukan, hal ini dapat dilihat dari 86 kombinasi rule yang dihasilkan. Tingkat keefektifan yang diperoleh dari pelatihan ini adalah $100 \%$. Kombinasi rule tersebut dapat dilihat pada hasil akhir pengolahan reduct program applikasi Rosseta.

Dilihat dari sebaran nilai yang diperoleh oleh peserta pelatihan, melalui transformasi data 1 ternyata nilai peserta kebanyakan lebih tinggi pada materi microsoft word. Peneliti menganalisa bahwa materi yang terdapat pada microsoft word ini sudah menjadi kegiatan sehari-hari yang mereka lakukan selama proses perkuliahan, misalnya membuat tugas, artikel ilmiah dan lain sebagainya Selain itu materi power point juga menjadi nilai yang tidak jauh berbeda dengan microsoft word hal ini berarti kreatifitas peserta pelatihan sangat tinggi, baik dalam membuat slide presentase yang bagus, bahkan mereka bisa megelola semua icon-icon yang ada sehingga membentuk sebuah presentasi yang sangat menarik. Sementara untuk nilai miscosoft excel peserta pelatihan cenderung mendapatkan nilai yang rendah, ini dikarenakan materi microsoft excel memerlukan analisa yang tinggi dalam pengolahan data.

\section{Kesimpulan}

Berdasarkan rule yang ditemukan maka diperoleh 24 kombinasi rule knowledge baru yang menyatakan bahwa pelatihan sertifikasi komputer dasar (Microsoft desktop training) ini 100\% efektif dilakukan. Untuk pengujian dengan program aplikasi Rosseta terdapat 86 kombinasi rule knowledge baru yang membuktikan bahwa pelatihan sertifikasi komputer dasar ini sangat efektif dilaksanakan. Untuk riset lanjutan akan diteliti efektivitas dari semua aspek yang mencakup aspek reaksi peserta, proses belajar, perubahan perilaku dan hasil.

\section{Referensi}

[1] Alliger, G. M., and Janak, E. A., "Kirkpatrick's levels of training criteria: Thirty years later," Personnel psychology, vol. 42, no. 2, pp. 331-342, 1989.

[2] Handayani, W. T., "Efektivitas Pelaksa-naan Pendidikan dan Pelatihan Kepemim-pinan Pegawai Negeri Sipil (Studi di Badan Kepegawaian Daerah Kabupaten Probolinggo)," Jurnal Administrasi Publik, vol. 3, no. 5, pp. 824-828, 2015.

[3] Haywood, K. M.. "Effective training: Toward a strategic approach," The Cornell Hotel and Restaurant Administration Quarterly, vol. 33, no. 6, pp. 43-52, 1992.

[4] Munir, Kerangka Kompetensi TIK bagi Guru. Bandung: Alfa Beta, 2014.

[5] Pawlak, Z., "Rough set theory and its applications to data analysis," Cybernetics \& Systems, vol. 29, no. 7, pp. 661-688, 1998.

[6] Rustiana, Ade, "Efektivitas Pelatihan bagi Peningkatan Kinerja Karyawan," Jurnal Dinamika Manajemen, vol. 1, no. 2, pp. 137143, 2010.

[7] Soelaiman, R., et al., "Penerapan Rough Set Quantitative Measure pada Aplikasi Pendukung Keputusan," in Proceeding of Seminar Nasional Teknoin., pp. 113-116, 2008.

[8] Mursanto, P. and Tomiarfi, A., "Penerapan Dominance-Based Rough Set Approach dalam Pemeringkatan Kualitas Desain Software Berorientasi Objek," Jurnal Sistem Informasi, vol. 5, no. 1, pp.8-14, 2012.

\section{Lampiran}

LAMPIRAN TABEL I

TRANSFORMASI DATA 1 SECARA LENGKAP

\begin{tabular}{|c|c|c|c|c|c|c|}
\hline \multirow{2}{*}{ No. Peserta } & \multicolumn{4}{|c|}{ Nilai } & \multirow{2}{*}{ Ket } & \multirow{2}{*}{ Keefektifan Pelatihan } \\
\hline & Word & Excel & Power point & Rata-rata & & \\
\hline 1 & $\mathrm{~A}$ & $\mathrm{C}$ & $\mathrm{C}$ & $\mathrm{C}$ & 1 & 1 \\
\hline 2 & B & $\mathrm{D}$ & $\mathrm{D}$ & $\mathrm{C}$ & 1 & 1 \\
\hline 3 & A & B & $\mathrm{C}$ & B & 1 & 1 \\
\hline 4 & B & $\mathrm{D}$ & $\mathrm{D}$ & $\mathrm{C}$ & 1 & 1 \\
\hline 5 & A & $\mathrm{D}$ & $\mathrm{D}$ & $\mathrm{C}$ & 1 & 1 \\
\hline 6 & A & $\mathrm{C}$ & B & $\mathrm{B}$ & 1 & 1 \\
\hline 7 & A & $\mathrm{D}$ & $\mathrm{D}$ & $\mathrm{C}$ & 1 & 1 \\
\hline 8 & B & $\mathrm{E}$ & $\mathrm{E}$ & $\mathrm{E}$ & 0 & 3 \\
\hline 9 & B & $\mathrm{D}$ & $\mathrm{D}$ & $\mathrm{C}$ & 1 & 1 \\
\hline 10 & A & $\mathrm{B}$ & $\mathrm{D}$ & $\mathrm{B}$ & 1 & 1 \\
\hline 11 & A & $\mathrm{D}$ & $\mathrm{D}$ & $\mathrm{C}$ & 1 & 1 \\
\hline 12 & A & $\mathrm{D}$ & $\mathrm{C}$ & $\mathrm{C}$ & 1 & 1 \\
\hline 13 & B & $\mathrm{D}$ & $\mathrm{D}$ & $\mathrm{C}$ & 1 & 1 \\
\hline 14 & $\mathrm{C}$ & $\mathrm{D}$ & $\mathrm{C}$ & $\mathrm{C}$ & 1 & 1 \\
\hline 15 & B & $\mathrm{E}$ & $\mathrm{E}$ & $\mathrm{E}$ & 0 & 3 \\
\hline
\end{tabular}


102 Jurnal Sistem Informasi (Journal of Information System), Volume 13, Issue 2, October 2017

LAMPIRAN TABEL I (Lanjutan)

TRANSFORMASI DATA 1 SECARA LENGKAP

\begin{tabular}{ccccccc}
\hline \multirow{2}{*}{ No. Peserta } & \multicolumn{9}{c}{ Nilai } & Ket & Keefektifan Pelatihan \\
\cline { 2 - 4 } & Word & Excel & Power point & Rata-rata & & \\
\hline 16 & D & E & E & E & 0 & 3 \\
17 & C & E & E & E & 0 & 3 \\
18 & E & E & E & E & 0 & 1 \\
19 & C & B & C & C & 1 & 1 \\
20 & A & B & C & B & 1 & 1 \\
21 & D & B & D & C & 1 & 1 \\
22 & B & A & B & B & 1 & 1 \\
23 & B & A & A & A & 1 & 1 \\
24 & D & C & D & D & 1 & 1 \\
25 & A & B & A & A & 1 & 1 \\
26 & C & B & C & C & 1 & 1 \\
27 & C & C & C & C & 1 & 1 \\
28 & E & E & E & E & 0 & 1 \\
29 & D & A & D & C & 1 & 1 \\
30 & B & D & D & C & 1 & 1 \\
31 & D & D & E & E & 0 & 1 \\
32 & C & D & A & C & 1 & 1 \\
33 & D & D & C & D & 1 & 1 \\
34 & C & D & C & C & 1 & 1 \\
35 & C & D & D & D & 1 & 1 \\
\hline
\end{tabular}

LAMPIRAN TABEL II

REDUCT

\begin{tabular}{|c|c|c|}
\hline CNF of Boolean Function & Prime Implicant & Reducts \\
\hline$(\mathrm{P} \wedge \mathrm{Q} \wedge \mathrm{R} \wedge \mathrm{S} \wedge \mathrm{T})$ & $(\mathrm{P} \wedge \mathrm{Q} \wedge \mathrm{R} \wedge \mathrm{S} \wedge \mathrm{T})$ & $\{\mathrm{P}, \mathrm{Q}, \mathrm{R}, \mathrm{S}, \mathrm{T}\}$ \\
\hline$(\mathrm{P} \wedge \mathrm{Q} \wedge \mathrm{R} \wedge \mathrm{S}) \vee(\mathrm{Q} \wedge \mathrm{R} \wedge \mathrm{S}) \vee(\mathrm{P} \wedge \mathrm{R} \wedge \mathrm{S})$ & $(R \wedge S) \wedge(Q \wedge T \vee P)$ & $\{\mathrm{R}, \mathrm{S}\},\{\mathrm{Q}, \mathrm{T}\},\{\mathrm{P}\}$ \\
\hline$(\mathrm{P} \wedge \mathrm{Q} \wedge \mathrm{R} \wedge \mathrm{S} \wedge \mathrm{T})$ & $(\mathrm{P} \wedge \mathrm{Q} \wedge \mathrm{R} \wedge \mathrm{S} \wedge \mathrm{T})$ & $\{\mathrm{P}, \mathrm{Q}, \mathrm{R}, \mathrm{S}, \mathrm{T}\}$ \\
\hline$(P \wedge Q \wedge R \wedge S \wedge T) \vee(P \wedge R \wedge S \wedge T)$ & $(P \wedge R \wedge S \wedge T)$ & $\{\mathrm{P}, \mathrm{R}, \mathrm{S}, \mathrm{T}\}$ \\
\hline$(\mathrm{P} \wedge \mathrm{Q} \wedge \mathrm{R} \wedge \mathrm{S} \wedge \mathrm{T})$ & $(P \wedge Q \wedge R \wedge S \wedge T)$ & $\{\mathrm{P}, \mathrm{Q}, \mathrm{R}, \mathrm{S}, \mathrm{T}\}$ \\
\hline$(P \wedge Q \wedge R \wedge S \wedge T) \vee(Q \wedge R \wedge S \wedge T) \vee P \vee Q$ & $(\mathrm{P} \vee \mathrm{Q})$ & $\{\mathrm{P}\},\{\mathrm{Q}\}$ \\
\hline$(P \wedge Q \wedge R \wedge S \wedge T) \vee(Q \wedge R \wedge S \wedge T)$ & $(\mathrm{Q} \wedge \mathrm{R} \wedge \mathrm{S} \wedge \mathrm{T})$ & $\{\mathrm{Q}, \mathrm{R}, \mathrm{S}, \mathrm{T}\}$ \\
\hline$(P \wedge Q \wedge R \wedge S \wedge T) \vee P \vee(Q \wedge R \wedge S) \vee(Q \wedge R \wedge S \wedge T) \vee Q$ & $(R \wedge S) \wedge(Q \vee T)$ & $\{\mathrm{R}, \mathrm{S}\},\},\{\mathrm{Q}\},\{\mathrm{T}\}$ \\
\hline$(P \wedge Q \wedge R \wedge S \wedge T) \vee(Q \wedge R \wedge S \wedge T) \vee P \vee(P \wedge Q)$ & $(Q \wedge R \wedge S \wedge T) \vee P$ & $\{\mathrm{Q}, \mathrm{R}, \mathrm{S}, \mathrm{T}\},\{\mathrm{P}\}$ \\
\hline$(P \wedge Q \wedge R \wedge S \wedge T) \vee(P \wedge Q \wedge R) \vee P$ & $\mathrm{P}$ & $\mathrm{P}$ \\
\hline$(P \wedge Q \wedge R \wedge S \wedge T) \vee(Q \wedge R \wedge S \wedge T)$ & $(\mathrm{Q} \wedge \mathrm{R} \wedge \mathrm{S} \wedge \mathrm{T})$ & $\{\mathrm{Q}, \mathrm{R}, \mathrm{S}, \mathrm{T}\}$ \\
\hline$(\mathrm{P} \wedge \mathrm{Q} \wedge \mathrm{R} \wedge \mathrm{S} \wedge \mathrm{T}) \vee(\mathrm{Q} \wedge \mathrm{R} \wedge \mathrm{S})$ & $(\mathrm{Q} \wedge \mathrm{R} \wedge \mathrm{S})$ & $\{\mathrm{Q}, \mathrm{R}, \mathrm{S}\}$ \\
\hline$(Q \wedge R \wedge S \wedge T) \vee(P \wedge Q \wedge R \wedge S \wedge T)$ & $(\mathrm{Q} \wedge \mathrm{R} \wedge \mathrm{S} \wedge \mathrm{T})$ & $\{\mathrm{Q}, \mathrm{R}, \mathrm{S}, \mathrm{T}\}$ \\
\hline$(P \wedge Q \wedge R \wedge S \wedge T) \vee(Q \wedge R \wedge S \wedge T)$ & $(\mathrm{Q} \wedge \mathrm{R} \wedge \mathrm{S} \wedge \mathrm{T})$ & $\{\mathrm{Q}, \mathrm{R}, \mathrm{S}, \mathrm{T}\}$ \\
\hline$(\mathrm{P} \wedge \mathrm{Q} \wedge \mathrm{R} \wedge \mathrm{S} \wedge \mathrm{T}) \vee(\mathrm{Q} \wedge \mathrm{R} \wedge \mathrm{S} \wedge \mathrm{T}) \vee(\mathrm{Q} \wedge \mathrm{R} \wedge \mathrm{S})$ & $(\mathrm{Q} \wedge \mathrm{R} \wedge \mathrm{S})$ & $\{\mathrm{Q}, \mathrm{R}, \mathrm{S}\}$ \\
\hline$(P \wedge Q \wedge R \wedge S \wedge T)$ & $(P \wedge Q \wedge R \wedge S \wedge T)$ & $\{P, Q, R, S, T\}$ \\
\hline$(\mathrm{P} \wedge \mathrm{Q} \wedge \mathrm{R} \wedge \mathrm{S} \wedge \mathrm{T})$ & $(P \wedge Q \wedge R \wedge S \wedge T)$ & $\{\mathrm{P}, \mathrm{Q}, \mathrm{R}, \mathrm{S}, \mathrm{T}\}$ \\
\hline$(P \wedge Q \wedge R \wedge S \wedge T) \vee(Q \wedge R \wedge S \wedge T)$ & $(\mathrm{Q} \wedge \mathrm{R} \wedge \mathrm{S} \wedge \mathrm{T})$ & $\{\mathrm{Q}, \mathrm{R}, \mathrm{S}, \mathrm{T}\}$ \\
\hline $\begin{array}{l}(P \wedge Q \wedge R \wedge S \wedge T) \vee(P \wedge R \wedge S \wedge T) \vee(P \wedge R \wedge S) \vee(P \wedge Q) \vee Q \vee \\
(P \wedge Q \wedge R) \vee(Q \wedge R \wedge S \wedge T) \vee(P \wedge Q \wedge S \wedge T) \vee(R \wedge S \wedge T)\end{array}$ & $(P \wedge R) \vee(R \wedge S \wedge T) \vee(P \wedge Q \wedge S \wedge T)$ & $\begin{array}{l}\{\mathrm{P}, \mathrm{R}\},\{\mathrm{R}, \mathrm{S}, \mathrm{T}\} \\
\{\mathrm{P}, \mathrm{Q}, \mathrm{S}, \mathrm{T}\}\end{array}$ \\
\hline$(P \wedge Q \wedge R \wedge S \wedge T) \vee(P \wedge Q \wedge S \wedge T)$ & $(\mathrm{P} \wedge \mathrm{Q} \wedge \mathrm{S} \wedge \mathrm{T})$ & $\{\mathrm{P}, \mathrm{Q}, \mathrm{R}, \mathrm{T}\}$ \\
\hline$(P \wedge Q \wedge R \wedge S \wedge T) \vee(Q \wedge R \wedge S \wedge T) \vee(R \wedge S \wedge T)$ & $(\mathrm{P} \wedge \mathrm{S} \wedge \mathrm{T})$ & $\{\mathrm{R}, \mathrm{S}, \mathrm{T}\}$ \\
\hline$(P \wedge Q \wedge R \wedge S \wedge T) \vee(P \wedge R \wedge S \wedge T)$ & $(P \wedge R \wedge S \wedge T)$ & $\{\mathrm{P}, \mathrm{R}, \mathrm{S}, \mathrm{T}\}$ \\
\hline$(\mathrm{P} \wedge \mathrm{Q} \wedge \mathrm{R} \wedge \mathrm{S} \wedge \mathrm{T})$ & $(P \wedge Q \wedge R \wedge S \wedge T)$ & $\{\mathrm{P}, \mathrm{Q}, \mathrm{R}, \mathrm{S}, \mathrm{T}\}$ \\
\hline$(\mathrm{P} \wedge \mathrm{Q} \wedge \mathrm{R} \wedge \mathrm{S} \wedge \mathrm{T})$ & $(P \wedge Q \wedge R \wedge S \wedge T)$ & $\{\mathrm{P}, \mathrm{Q}, \mathrm{R}, \mathrm{S}, \mathrm{T}\}$ \\
\hline
\end{tabular}

